\section{V \\ VERSITA}

Folia Oeconomica Stetinensia

DOI: $10.2478 / \mathrm{v} 10031-012-0031-8$

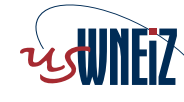

Wydzial Nauk Ekonomicznych i Zarządzania Uniwersytetu Szczecínskiego

\title{
INFLUENCE OF THE AMERICAN FINANCIAL MARKET ON OTHER MARKETS DURING THE SUBPRIME CRISIS*
}

Piotr Płuciennik, Ph.D.

Adam Mickiewicz University

Faculty of Mathematics and Computer Science

Laboratory of Financial Econometrics

Umultowska 87, 61-614 Poznań, Poland

e-mail:pplucien@amu.edu.pl

Received 14 November 2012, Accepted 17 April 2013

\begin{abstract}
Subprime crisis which started in the USA in 2007 was the cause of the most significant economic disturbances since the Great Depression in 1930s. Soon it transmitted to other countries, including those in which banks were not engaged in the subprime mortgage market. The crisis hit various sectors of national economies and led to changing of the trends on the stock markets, which are connected to American capital market. In the following article we researched the influence of the American market on the other markets in the context of the financial crisis. Our analysis is based on the results obtained from the multivariate parametric models. Seeing that the data space is high-dimensional, we used GO-GARCH models introduced by van der Weide (2005) and Boswijk and van der Weide (2006).
\end{abstract}

Keywords: principal components analysis, impulse response function, stock index, multidimensional models of conditional variance.

JEL classification: C32, G19.

This work was financed from the Polish science budget resources in the years 2010-2013 as the research project N N111 035139. 


\section{Introduction}

When on July 19, 2007 Dow Jones Industrial passed 14,000 for the first time in its history, Henry Paulson, then Secretary of the Treasury under George W. Bush, said the global economy had never been in such a good condition in his lifetime. In reality, due to popularity of the (almost perfect) subprime mortgages in the United States, mortgage lenders were already experiencing problems. Ownit Mortgage Solutions Inc., the first American institution to offer subprime mortgages, bankrupted as soon as on January 3, 2007. Financial markets reacted calmly. Serious liquidity problems of the banks offering subprime mortgages were revealed in the second half of July 2007. They originated in the loss of investors' trust which hit banks in the United States and other countries. In spite of the fast reaction by FED and central banks of Australia, Canada and Japan, which provided the markets with about 300 billion dollars in order to save the banks from loss of liquidity, the world financial crisis started ${ }^{1}$. The crisis affected also the capital markets, leading to their consistent decline till the end of March 2009.

The world stock markets are influenced by the US stock exchanges. This is true also for the stock exchanges in the countries loosely connected to American economy, such as the Warsaw Stock Exchange. In the following paper we try to verify if the subprime mortgages crisis in the United States, which spread rapidly to other countries, led to increased influence the US stock exchange had on their stock exchanges. We analyzed series of logarithmic returns of the main stock indexes from various countries during a 3 years period preceding and a period following the start of the subprime crisis, which ended in March 2009. We apply multidimensional GARCH models to the series, and use them to determine impulse response functions in conditional variance, which will show us how the indexes affect one another.

Serious flaw of the popular multidimensional parametric models of conditional variance like BEKK model ${ }^{2}, \mathrm{CCC}^{3}$ and $\mathrm{DCC}^{4}$ is the number of parameters of the model rapidly growing with the increase of number of the modeled time series. Even in the relatively simple diagonal $\operatorname{BEKK}(1,1,1)$ model the number of parameters is $3 k(k+1) / 2$, where $k$ is the number of the modeled time series, which would equal as much as 45 parameters for five stock indexes analyzed in this paper. For this reason we decided to use GO-GARCH model (Generalized Orthogonal GARCH), proposed by van der $\mathrm{Weide}^{5}$, which is a generalized and improved version of O-GARCH (Orthogonal GARCH) model introduced by Alexander and Chibumba ${ }^{6}$.

Unfortunately, introduced by Haffner and Herwartz VIRF function (Volatility Impulse Response Function) is designated only for the BEKK models ${ }^{7}$. For that reason, to determine directions of volatility transmission, we analyze properties of conditional variances obtained by 
using GO-GARCH model, then we fit VAR model and determine the standard impulse response functions.

\section{Models}

As mentioned in the previous section, we used GO-GARCH (Generalized Orthogonal GARCH) model to describe conditional variance of stock indexes. It is an improved version of model introduced by Alexander \& Chibumba, and developed by Alexander and Klassen ${ }^{8}$, called O-GARCH (Orthogonal GARCH), The idea of the O-GARCH $(p, q)$ is to apply univariate $\operatorname{GARCH}(p, q)$ model to each of the $m$ principal components of $k$-dimensional data. The O-GARCH model reduced the problem of modeling the $k \cdot k$ conditional covariance matrix to estimating $m$ independent GARCH models $(m \leq k)$. The conditional covariance matrix is described by the following equation

$$
H_{t}=A D_{t} A^{\prime}
$$

where $D_{t}$ is the diagonal $m \cdot m$ dimensional matrix of principal components conditional variance, and $A$ is $k \cdot m$ matrix named by author, the matrix of factor weights". The $H_{t}$ matrix is usually semipositive-definite only if $m<<k^{9}$, Hence the O-GARCH bases on the assumption of absence of conditional covariance between principal components, but in fact only the unconditional covariance does not exist. The $A$ should also be the orthogonal matrix. If the analyzed series are low correlated, then the condition are hardly attainable ${ }^{10}$.

Proposed by van der Weide GO-GARCH model, which we use in this paper, is free from most of the aforementioned limitations of the O-GARCH model ${ }^{11}$. The main difference between the two models is that in the former the $A$ matrix is being multiplied by an orthogonal matrix with the unit determinant defined as a product of $k(k-1) / 2$ rotation matrices:

$$
U=\prod_{i<j} G_{i j}\left(\theta_{i j}\right),-\pi<\theta_{i j}<\pi, i, j=1,2, \ldots, k
$$

where $G_{i j}\left(\theta_{i j}\right)$ performs a rotation in the plane spanned by the $i$-th and the $j$-th vectors of the canonical basis of $R^{k}$ over an angle $\theta_{i j}$. Angles $\theta_{i j}$ are estimated along with other parameters of the GO-GARCH model by the maximum likelihood method ${ }^{12}$. Thanks to this modification the $A$ matrix does not have to be orthogonal, as it is sufficient if it is nonsingular. Furthermore, in the GO-GARCH model the semi positive-define conditions for correlation matrix are easy to fulfill $^{13}$. For this reason the GO-GARCH model can use all components, while the O-GARCH can be applied only for a couple of principal components. 
Unfortunately, there are limitations to the approach introduced by van der Weide ${ }^{14}$. Dependence of the $U$ matrix on $k(k-1) / 2$ number of parameters makes it impossible to apply this model to very high-dimensional time series. In the newer version of the GO-GARCH model (called GO-GARCH-NLS), introduced by Boswijk and van der Weide ${ }^{15}$, the $U$ matrix is determined by using matrix regression with $2 k$ parameters estimated with the nonlinear least squares method ${ }^{16}$. In the following paper we consider only 5-dimensional time series. In both cases there is only 10 additional parameters, however in the newer version of the GO-GARCH the parameters of the $U$ matrix and any univariate GARCH model are estimated separately.

To describe each principal component we use standard GARCH $(1,1)$ model in the following specification

$$
\begin{aligned}
& y_{t}=\sigma_{t} \varepsilon_{t} \\
& \sigma_{t}^{2}=\sigma^{2}(1-\alpha-\beta)+\alpha y_{t-1}^{2}+\beta \sigma_{t-1}^{2}
\end{aligned}
$$

We use variance-targeting method to estimate parameters of the model ${ }^{17}$.

The GO-GARCH models are not a frequently used, because they are difficult to implement. However, for their advantages they were used in a couple of interesting studies. In the World Bank report the model was the basis for volatility analysis of Malaysian market in comparison to other markets, Vojtek and Kliber, Kliber, Płuciennik used it to study relations between interest rates of inter bank market ${ }^{18}$.

\section{Data}

We analyze the main stock indexes of the United States, Japan, Germany, Great Britain and Poland. The subprime crisis started in the summer of $2007^{19}$, To determine the exact date dividing the period into "before" and "during" the crisis we analyze the 1- and 3-month LIBOR-OIS spreads for the US dollar, which reflect the fear of contractor's insolvency in the inter bank market ${ }^{20}$ and the levels of the Dow Jones Industrial index.

There were manipulations of the LIBOR and EURIBOR rates revealed in 2012 and subsequently Barclays Bank was fined a total of about 450 million USD. It led to weakening trust in the official inter bank rates as well as the LIBOR-OIS spreads credibility. However, the studies by Schwarz ${ }^{21}$ conducted on 30\% of all inter bank loans show that before August 2007 the LIBOR rate understated the real cost of 3-month loan by about 1 basis point and after August 2007 by about 5 basis points. 
The LIBOR-OIS spreads started to rise in the second half of July 2007, but sudden large growth occurred on August 9, 2007 when BNP Paribas suspended with drawals from three funds investing in the bonds secured by subprime mortgages, because turbulences on the financial markets made it impossible to price their assets. It was an important date in the process of unfolding of the crisis $^{22}$, so we chose it for this paper as the date dividing the "before" and "during" the crisis subperiods.

Table 1. The descriptive statistics of logarithmic returns of the main stock indexes of the United States, Japan, Germany, Great Britain and Poland

\begin{tabular}{|l|c|c|c|c|c|c|}
\cline { 2 - 7 } \multicolumn{1}{c|}{} & Mean & Std. dev. & Skewness & Kurtosis & Min. & Max. \\
\hline \multicolumn{7}{|c|}{9 August 2004-8 August 2007 } \\
\hline DAX & 0.094204 & 0.89587 & -0.348770 & 6.90075 & -3.4631 & 2.6612 \\
\hline DowJones & 0.043642 & 0.66086 & -0.305730 & 7.42980 & -3.3487 & 2.1529 \\
\hline FTSE100 & 0.051249 & 0.70441 & -0.413960 & 8.09770 & -3.1972 & 2.6046 \\
\hline NIKKEI225 & 0.058063 & 1.00920 & -0.362540 & 7.51190 & -4.2304 & 3.5220 \\
\hline WIG20 & 0.101600 & 1.30560 & -0.352050 & 7.51010 & -5.7306 & 4.7553 \\
\hline \multicolumn{7}{|c|}{9 August $2007-10$ March 2009 } \\
\hline DAX & -0.148640 & 2.17840 & 0.697580 & 3.69758 & -7.4335 & 20.7970 \\
\hline Dow_Jones & -0.162960 & 2.11510 & 0.187550 & 7.31010 & -8.2005 & 10.5080 \\
\hline FTSE100 & -0.131210 & 2.12150 & 0.096345 & 6.65470 & -9.2656 & 9.3843 \\
\hline NIKKEI225 & -0.222920 & 2.54030 & -0.347920 & 7.99260 & -12.1110 & 13.2350 \\
\hline WIG20 & -0.220090 & 2.25930 & -0.396460 & 5.52940 & -11.6860 & 8.1548 \\
\hline
\end{tabular}

Source: own calculations.

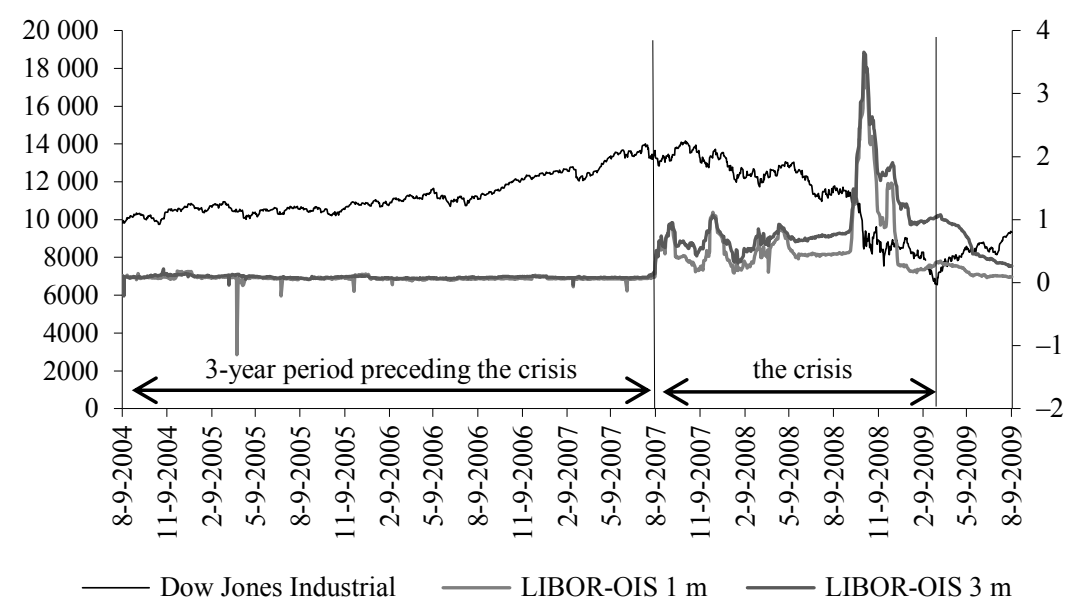

Fig. 1. The Dow Jones Industrial levels (primary axis) and 1- and 3-month LIBOR-OIS spreads for the United States (secondary axis) from 9 August 2007 to 10 March 2009

Source: own calculations. 
Soon after the growth of the LIBOR-OIS spreads the volatility of the Dow Jones Industrial index raised and the upward trend changed for the downward for the first time in several years. The index marked the biggest loss shortly after the collapse of Lehman Brothers when the LIBOR-OIS spreads were reaching highest values. As the date of the end of the subprime mortgage crisis and the end of the second analyzed subperiod we chose March 10, 2009 when the Dow Jones Industirial downward trend changed for the upward and the LIBOR-OIS spreads started to fall fast and steadily. The descriptive statistics of logarithmic returns of the indexes from two analyzed subperiods are presented in the Table 1.

\section{Empirical research}

We apply GO-GARCH $(1,1)$ models to logarithmic returns of the stock indexes for both analyzed subperiods to obtain conditional variances, to which in turnwe fitthe VAR/VECM model in order to determine the impulse response functions. Analysis of these functions reflect how much variances of different indexes affect one another.

Table 2. Parameters estimates obtained from the GO-GARCH $(1,1)$ model applied to logarithmic returns of the main stock indexes of the United States, Japan, Germany, Great Britain and Poland

\begin{tabular}{|c|c|c|c|c|c|c|}
\hline \multirow{2}{*}{ Par. } & \multicolumn{3}{|c|}{9 August $2004-8$ August 2007} & \multicolumn{3}{|c|}{9 August 2007 - 10 March 2009} \\
\hline & estimate & std. error & $p$-value & estimate & std. error & $p$-value \\
\hline \multicolumn{7}{|c|}{$1^{\text {st }}$ principal component } \\
\hline$\alpha$ & 0.091849 & 0.0320490 & 0.0043 & 0.134099 & 0.036963 & 0.0003 \\
\hline$\beta$ & 0.824365 & 0.0736850 & 0 & 0.844475 & 0.046215 & 0 \\
\hline$\sigma^{2}$ & 0.083786 & --- & --- & 0.021426 & --- & --- \\
\hline \multicolumn{7}{|c|}{$2^{\text {nd }}$ principal component } \\
\hline$\alpha$ & 0.024446 & 0.0092099 & 0.0081 & 0.213706 & 0.049583 & 0 \\
\hline$\beta$ & 0.955938 & 0.0187670 & 0 & 0.779152 & 0.052582 & 0 \\
\hline$\sigma^{2}$ & 0.019616 & --- & --- & 0.007143 & --- & --- \\
\hline \multicolumn{7}{|c|}{$3^{\text {rd }}$ principal component } \\
\hline$\alpha$ & 0.043995 & 0.0159170 & 0.0058 & 0.121753 & 0.053833 & 0.0243 \\
\hline$\beta$ & 0.926569 & 0.0278230 & 0 & 0.852970 & 0.073456 & 0 \\
\hline$\sigma^{2}$ & 0.029437 & --- & --- & 0.025277 & --- & --- \\
\hline \multicolumn{7}{|c|}{$4^{\text {th }}$ principal component } \\
\hline$\alpha$ & 0.037624 & 0.0160120 & 0.0190 & 0.081034 & 0.045786 & 0.0775 \\
\hline$\beta$ & 0.913999 & 0.0389560 & 0 & 0.899998 & 0.064275 & 0 \\
\hline$\sigma^{2}$ & 0.048378 & --- & --- & 0.018968 & --- & --- \\
\hline \multicolumn{7}{|c|}{$5^{\text {th }}$ principal component } \\
\hline$\alpha$ & 0.127223 & 0.0264140 & 0 & 0.113105 & 0.024363 & 0 \\
\hline$\beta$ & 0.752126 & 0.0461050 & 0 & 0.870096 & 0.031010 & 0 \\
\hline$\sigma^{2}$ & 0.120651 & --- & --- & 0.016800 & --- & --- \\
\hline
\end{tabular}

Source: own calculations. 
In Table 2 we present results of estimations of the GO-GARCH model applied to two analyzed subperiods. In neither of them we found any linear dependency in series of logarithmic returns of the stock indexes levels. In the results of the estimation we present only parameters describing five principal components, omitting numerous parameters of $A$ and $U$ matrices.

Principal components reflect properties of the analyzed logarithmic return series. In both subperiods for all components the sum of $\alpha$ and $\beta$ is close to 1 , which indicates slowly decreasing autocorrelation of squared logarithmic returns series. This is typical of series of logarithmic returns of the stock indexes levels and indicates large variability of conditional variances in time.
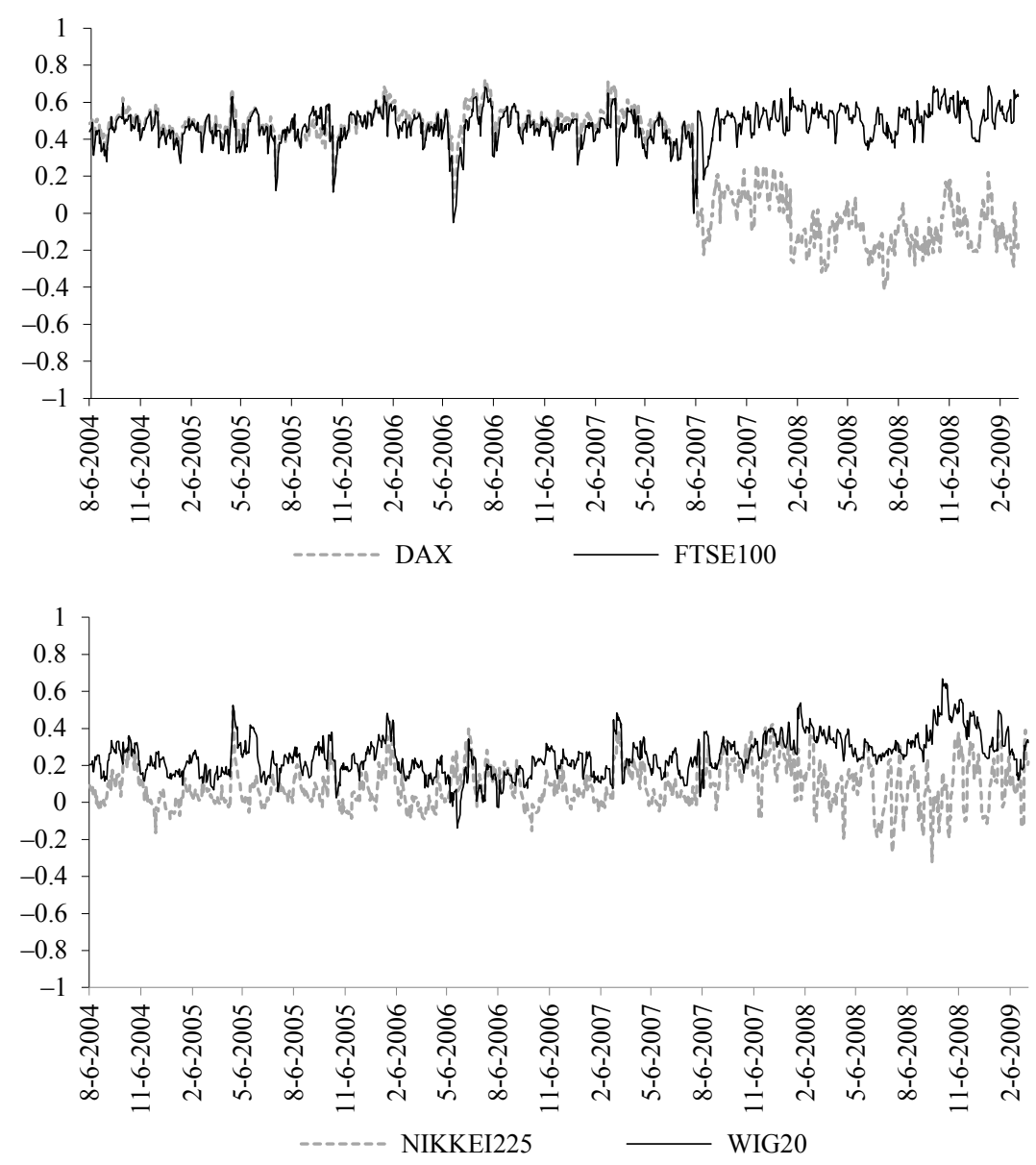

Fig. 2. Conditional correlations between the logarithmic return of the Dow Jones Industrial and logarithmic return of otherstock indexes before and duringthe crisis

Source: own calculations. 
In Figure 2 we present conditional correlations of the logarithmic returns series obtained from the GO-GARCH model fitting. Since the beginning of the crisis we can observe big growthof the correlation betweenthe Dow Jones Industrial,and the FTSE100 and the WIG20 indexes respectively. In case of the NIKKEI225 index, its conditional correlation does not rise, but its dynamics does. What seems surprising is fall of the correlation between the Dow Jones Industrial and the DAX. It should be noted that conditional correlation illustrates only linear dependencies. Considering that the trend of the DAX index changed similarly to all other analyzed indexes, we assume that correlation between German and American indexes did not disappear but changed. To prove this, in the next part of this paper we will apply the VAR model to conditional variance,obtained by using the GO-GARCH model, to determine the impulse response functions to a unit Dow Jones Industrial impulse. The functions will illustrate transmission of the crisis of confidence from American to other markets. Since Johansen's (1991) test affirmed the presence of cointegration in the series of conditional variances for both
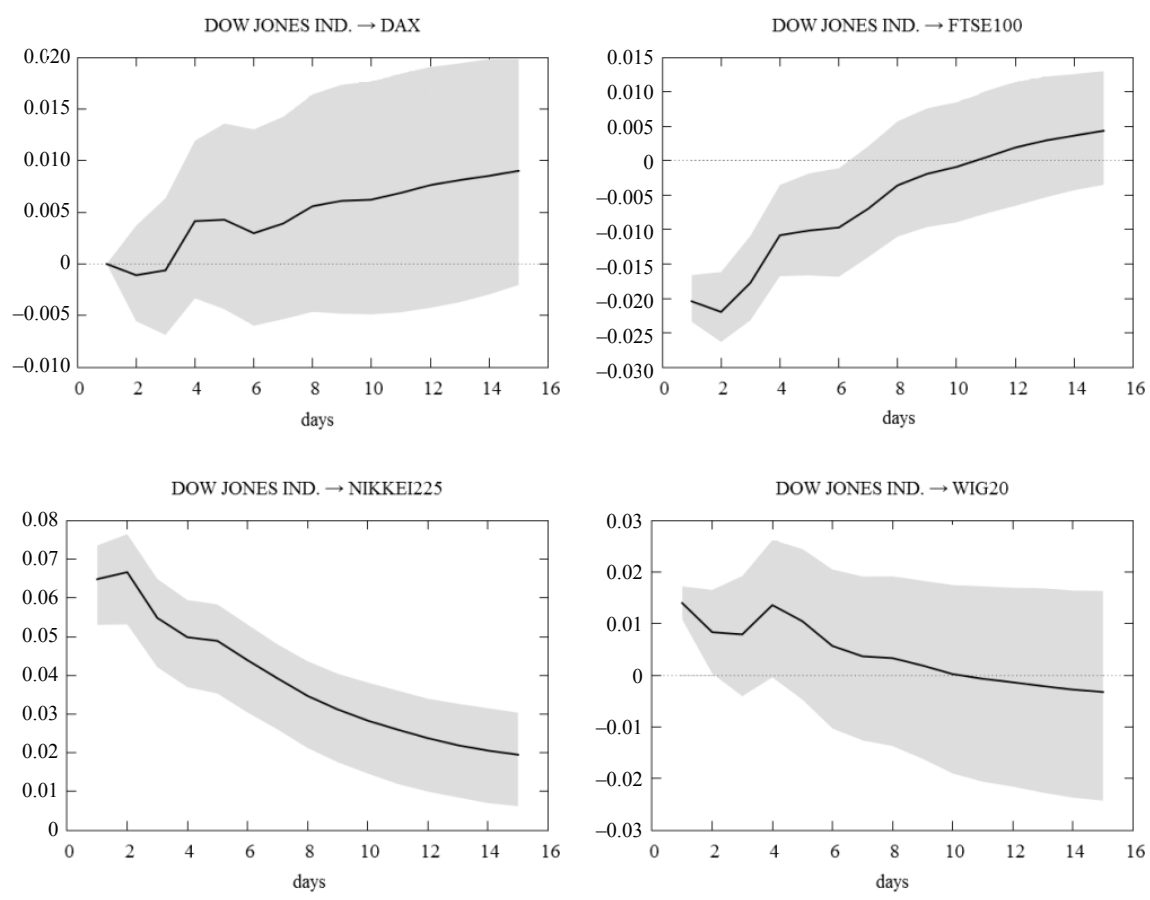

Fig. 3. Impulse response functions of conditional variance of DAX, FTSE, NIKKEI225, WIG20 indexes to a unit disturbance of Dow Jones Industrial in between 9 August 2004 and 8 August 2007.

Source: own calculations. 
analyzed subperiods, impulse response functions were obtained by using the VECM model. The impulse response functions with 90\% confidence interval are presented in Figures 3 and 4.
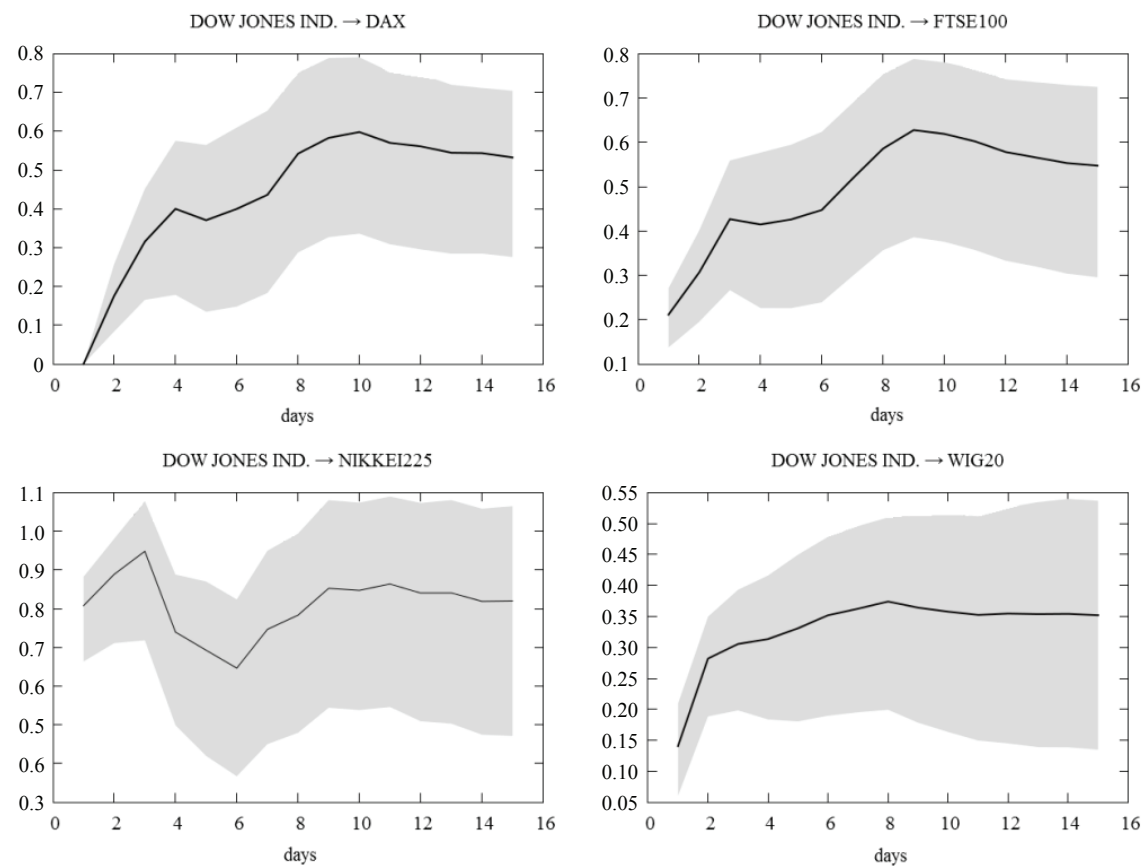

Fig. 4. Impulse response functions of conditional variance of DAX, FTSE, NIKKEI225, WIG20 indexes to a unit disturbance of Dow Jones Industrial in between 9 August 2007 and 10 March 2009.

Source: own calculations.

Although the conditional correlation did not illustrate it, the change in how American indexes influence European and Japanese indexes can be interpreted from the impulse response functions. Very low before the crisis, the reaction to a unit disturbance in the American market became strong after the crisis began. Japanese index had the strongest reaction, as a result of a high level of engagement of Japanese banks in the subprime mortgage market. Reaction of the Polish index is the smallest because Polish banks did not invest significant part of their capital abroad and seldom outside their respective bank groups. The main reason for problems of the banking sector in Poland was transmission of the confidence crisis; the cause for recession in Polish economy was declining export. In the case of German index, for which autocorrelation after the crisis began was close to zero, graphs of the impulse response functions show that 
confidence crisis transmitted from American to the German market as fast as it did to the British market.

\section{Conclusions}

The results of analysis in this paper show that the subprime crisis had a great influence on global financial markets. First signals of subprime crisis in USA became the impulse to start a very deep correction in all important world capital markets. Conditional correlation between the main stock indices in the USA and in other markets did not increase remarkably (the conditional correlation between the Dow Jones and DAX falls after August 2007), The analysis of impulse response functions determined for conditional variance series showed that the crisis increased the power of transmission of nervousness from American to other markets. The reaction to disturbances on American market is also more durable during the crisis compared to pre-crisis period. Therefore, we can conclude that during the subprime crisis the American market was observed more closely by financial markets investors in Europe and Japan, and its performance was an important factor in making investment decisions.

\section{Notes}

${ }^{1}$ More about the cause of the subprime mortgage crisis is to be found in the Financial Services Authority (2009), Study of the subprime crisis changing into the world financial crisis was conducted by Mishkin (2011).

2 Engle, Kroner (1995).

${ }^{3}$ Bollerslev (1990).

${ }^{4}$ Engle (2002).

5 van der Weide (2002).

${ }^{6}$ Alexander, Chibumba (1996).

${ }^{7}$ Haffner, Herwartz (1998).

${ }^{8}$ Alexander, Chibumba (1996); Alexander (2000), Alexander (2001); Klassen (2000).

${ }^{9}$ See Alexander (2000); Alexander (2001).

${ }_{10}$ See van der Weide (2002).

11 Ibidem.

12 See ibidem; Laurent (2009).

13 See van der Weide (2002).

14 Ibidem.

15 Boswijk and van der Weide (2006).

${ }^{16}$ See ibidem; Laurent (2009).

${ }^{17}$ See ibidem.

${ }^{18}$ The World Bank (2010); Vojtek (2003); Kliber, Kliber, Płuciennik (2012). 
19 See Blackburn (2008); Tudor (2009).

${ }^{20}$ See Sengupta, Yu (2008); Thornton (2009).

${ }^{21}$ Schwarz (2009).

22 See Konopczak at al. (2010).

\section{References}

Alexander, C.O. (2000). Orthogonal Methods for generating Large Positive Semidefinite Covariance Matrices. ISMA Centre Disscussion Papers in Finance 2000-2006, University of Reading, UK.

Alexander, C.O. (2001). Orthogonal GARCH in C.O. Alexander (Ed.) Mastering Risk, 2, Financial Times Prentice Hall.

Alexander, C.O. \& Chibumba, A. (1996), Multivariate orthogonal factor GARCH. University of Sussex Discussion Paper in Mathematics.

Blackburn, R. (2008). The Subprime Crisis. New Left Review, 50, March, April.

Bollerslev, T. (1990), Modelling the Coherence in Short-Run Nominal Exchange Rate: A Multivariate Generalized ARCH Approach. Review of Economics and Statistic, 72, 498-505.

Boswijk, H. \& van der Weide R. (2006). Wake me up before you GO-GARCH. UvA-Econometrics Discussion Paper 2006/03.

Engle, R. (2002). Dynamic Conditional Correlation - a simple class of Multivariate GARCH models. Journal of Business and Economic Statistic, 20, 339-350.

Engle, R. \& Kroner, F. (1995). Multivariate simultaneous generalized ARCH. Econometric Theory, 11, 122-150.

Financial Services Authority (2009). The Turner Review. A regulatory response to the global banking crisis, March, www.fsa.gov.uk (31.01.2011).

Haffner, C.M. \& Herwartz, H. (1998). Volatility Impulse Response Functions for Multivariate GARCH Models. CoreDiscussion Paper 9847.

Johansen, S. (1991). Estimation and Hypothesis Testing of Cointegration Vectors in Gaussian Vector Autoregressive Models. Econometrica, 59 (6), 1551-1580.

Klassen, F. (2000), Have Exchange Rates Become Mode Closely Tied? Evidence from a new Multivariate GARCH model. Centre for Economic Research discussion paper, University of Tilburg.

Kliber, A., Kliber, P. \& Płuciennik, P. (2012), Dependencies between interbank interest rates in Poland (in Polish). Przegląd Statystyczny, 2012-II, 151-164. 
Konopczak, M., Sieradzki, R. \& Wiernicki, M. (2010). Global financial markets crisis - impact on the Polish financial market and implications for the real sector of the economy (in Polish). Bank i Kredyt, 41 (6), 45-70.

Laurent, S. (2009), G@RCH 6, Estimating and Forecasting ARCH Models. London: Timberlake Consultants Press.

Mishkin, F. (2011), Over the Cliff: From the Subprime to the Global Financial Crisis. Journal of Economic Perspectives 25 (1), Winter 2011, 49-70.

Schwarz, K. (2009), Mind the gap: disentangling credit and liquidity in risk spreads, working paper of University of Pennsylvania Wharton School of Business.

Sengupta, R. \& Yu, M.T. (2008). The LIBOR-OIS Spread as a Summary Indicator. Economic Synopses, 25, Federal Reserve Bank of St. Louis.

The World Bank (2010). Growth throught Innovations. Malaysia Economic Monitor.

Thornton, D.L. (2009), What the Libor-OIS Spread Says. Economic Synopses, 24, Federal Reserve Bank of St. Louis.

Tudor, C. (2009), Understanding the Roots of the US Subprime Crisis and its Subsequent Effects. The Romanian Economic Journal, Year XII, 31 (1).

Vojtek, M. (2003). Calibration of interest rate models - transition markets case. CERGE-EI Discussion Paper Series.

van der Weide R. (2002). GO-GARCH: A Multivariate Generalized Orthogonal GARCH Model. Journal of Applied Econometrics, 17, 549-564. 